\title{
El futuro del empleo público local: retos ante un mundo digital
}

\author{
The future of local public employment: challenges in a digital world \\ Concepción Campos Acuña \\ Ayuntamiento de Vigo (España) \\ ORCID: https://orcid.org/0000-0002-7718-8000 \\ concepcion.campos@vigo.org
}

\section{NOTA BIOGRÁFICA}

Doctora en Derecho, Secretaria de Administración Local, Académica correspondiente de la Real Academia de Legislación y Jurisprudencia, Codirectora de Red Localis y Presidenta de la Asociación de Mujeres en el Sector Público. Autora de múltiples publicaciones en revistas especializadas, Directora de distintas obras colectivas, pertenece a distintos Consejos editoriales, y es colaboradora habitual en procesos de reforma de administración pública.

\section{RESUMEN}

El sector público se encuentra abocado a un proceso de reflexión sobre la transformación que necesita para adecuarse a la sociedad del conocimiento, fuertemente marcada por la tecnología y su efecto disruptivo en el modelo de gestión. En este contexto, el éxito en los retos de futuro que debe abordar sólo serán posibles en el marco de un diseño adecuado del empleo público, diseño que examinamos en el presente trabajo desde la óptica del ámbito local. Para ello se analizarán sus peculiaridades en una organización territorial compleja, y con una planta local que, por su dimensionamiento, condiciona la disponibilidad de los recursos humanos precisos para la adecuación de la administración a las necesidades de la ciudadanía. El factor digital exige situar en el centro de la reflexión tanto el completo proceso de incorporación de personas al servicio público, con las dificultades en la captación del talento, como en el desempeño del mismo, siendo preciso articular un haz de competencias profesionales que permita responder acertadamente al nuevo modelo de gestión pública. Tras el análisis y la reflexión se formulan una serie de propuestas, enunciando líneas claves para rediseñar el modelo de empleo público local sin necesidad de modificar su marco normativo.

\section{PALABRAS CLAVE}

Empleo; futuro; digital; local; gobierno.

\begin{abstract}
The public sector is engaged in a process of reflection on the transformation it needs to adapt to the knowledge society, strongly marked by technology and its disruptive effect on the management model. In this context, success in the future challenges that it must address will only be possible within the framework of an adequate design of public employment, a design that we examine in this paper from the local perspective. For this, its peculiarities will be analyzed in a complex territorial organization, and with a local plant that, due to its size, conditions the availability of the human resources required to adapt the administration to the needs of the citizens. The digital factor requires placing at the center of reflection both the complete process of incorporation of people into the public service, with the difficulties in attracting talent, as well as in the performance of it, being necessary to articulate a bundle of professional skills that allows responding rightly to the new model of public management. After analysis and reflection, a series of proposals are formulated, setting out key lines to redesign the local public employment model without the need to modify its regulatory framework.
\end{abstract}

\section{KEYWORDS}

Employment; future; digital; local; government. 


\begin{abstract}
SUMARIO
INTRODUCCIÓN. 1. LAS PECULIARIDADES DEL MUNDO LOCAL Y SU PROYECCIÓN EN EL MODELO DE EMPLEO PÚBLICO. 1.1. EL DIMENSIONAMIENTO DE LA PLANTA LOCAL COMO FACTOR LIMITATIVO DEL CAMBIO. 1.2. LAS ENTIDADES LOCALES COMO PRESTADORAS DE SERVICIOS BÁSICOS A LA CIUDADANÍA. 1.3. MARCO NORMATIVO DE APLICACIÓN AL EMPLEO PÚBLICO LOCAL. 2. APROXIMACIÓN A LAS PATOLOGÍAS EN LA DEFINICIÓN DEL MODELO DE GESTIÓN DE PERSONAS. 2.1. DISFUNCIONES COMUNES EN LA GESTIÓN DE PERSONAS. 2.2. LA INEXISTENTE DIRECCIÓN PÚBLICA PROFESIONAL Y EL PAPEL DE LOS FUNCIONARIOS DE HABILITACIÓN NACIONAL. 3. LOS RETOS DEL EMPLEO PÚBLICO LOCAL EN EL S. XXI. 3.1. ENFOCANDO NECESIDADES DEL EMPLEO PÚBLICO LOCAL DESDE LA OBSOLESCENCIA DEL MODELO ACTUAL. 3.2. SELECCIONANDO PERSONAL DEL S. XXI CON MÉTODOS DEL S. XX: CÓMO AVANZAR. 3.3. EL APRENDIZAJE CONTINUO EN TIEMPOS LÍQUIDOS: PRACTICANDO EL RESKILLING. 4. COMPETENCIAS NECESARIAS EN LA DEFINICIÓN DE LOS PERFILES PROFESIONALES DEL MUNDO LOCAL. 4.1. COMPETENCIAS DIGITALES: ARTICULANDO LAS BASES DE LA EVOLUCIÓN TECNOLÓGICA. 4.2. TELETRABAJO EN EL ÁMBITO LOCAL Y LA CONFIGURACIÓN DEL PUESTO DE TRABAJO $360^{\circ}$. 4.3. IMPACTO DE LA INTELIGENCIA ARTIFICIAL Y LA ROBOTIZACIÓN EN EL EMPLEO PÚBLICO LOCAL. 4.4. DIFICULTADES EN LA INTRODUCCIÓN Y EVALUACIÓN DE SOFT SKILLS EN EL EMPLEO PÚBLICO LOCAL. 5. RECAPITULANDO EL ESTADO DE LA CUESTIÓN Y PERSPECTIVAS DE REFORMA. 5.1 REPENSANDO EL MODELO DESDE EL DEBATE MULTILATERAL. 5.2. PROPUESTAS DE AJUSTE EN EL EMPLEO PÚBLICO LOCAL PARA UN FUTURO QUE YA ES PRESENTE. CONCLUSIONES. REFERENCIAS BIBLIOGRÁFICAS.
\end{abstract}

\title{
INTRODUCCIÓN
}

Desde comienzos del s. XXI vivimos inmersos en nuevas realidades que presentan un mundo en continua evolución y sometido a la transformación e innovación que trae consigo la tecnología, avances a los que las administraciones públicas en general, y las locales, en particular, no pueden ignorar, siguiendo su tradicional inmovilismo frente a los cambios. La aparición de las nuevas tecnologías en el último cuarto del s. XX y la fuerza de su irrupción en el conjunto de la sociedad en el s. XXI a un ritmo vertiginoso que resulta difícil seguir en el peculiar calendario de la gestión pública exigen, demandan una completa transformación. Un proceso de transformación que debe ser objeto de liderazgo, liderazgo que no puede asumirse únicamente en torno a consideraciones y cuestiones tecnológicas, sino desde la organización y la gestión de personas, que se convertirán en el elemento diferencial de la gestión pública.

Porque «la transformación digital de la sociedad española no puede hacerse al margen de la Administración Pública ni dejando incólume el empleo público. La disrupción tecnológica vendrá acompañada de disrupción organizativa y funcional» (Jiménez, 2020), el futuro del empleo público, en general, y local, en particular, está directamente relacionado con la capacidad para completar el proceso de transformación, para convertir administraciones del s. XX en administraciones del s. XXI, para liderar el futuro desde lo público. Y a tal fin serán necesarias personas con competencias para diagnosticar y resolver problemas, con la visión sistémica, y con aspectos diferentes de su personalidad como la iniciativa, la creatividad, la curiosidad y la imaginación, con las soft skills. Por ello, resulta necesario abordar ya, sin más dilación y procrastinación la revisión del modelo de empleo público local.

Parece bastante unánime el consenso sobre la circunstancia de que el gran cambio que se avecina en la organización futura del trabajo vendrá de la mano de la robótica y la inteligencia artificial, por lo que las administraciones públicas no pueden dejar de plantearse los retos de futuro inminentes que se presentan para la interiorización de los nuevos modelos de trabajo y de gestión, entendiendo precisamente que esa robotización y la utilización de la inteligencia artificial exigirán la revisión del modelo en profundidad, capitalizando el talento de los empleados para generar mayor valor público, poniendo en valor las destrezas y habilidades no automatizables, buscando el adecuado equilibrio y combinación entre la inteligencia artificial y la inteligencia emocional.

Este escenario disruptivo de la tecnología se ha visto intensificado por un factor exógeno e imprevisible, la declaración de la pandemia por la Organización Mundial de la Salud (OMS) en marzo de 2020 por la COVID-19, situándonos definitivamente, ante lo que se conocía ya como tiempos VUCA, expresión que describe, por sus siglas en inglés, un entorno caracterizado por la Volatilidad (Volatility), la Incertidumbre (Uncertainty), la Complejidad (Complexity) y la Ambigüedad (Ambiguity). Y es en este entorno VUCA tan 
marcado por la globalización y la disrupción tecnológica, en el que los sistemas públicos afrontan desafíos importantes, una parte de los cuales tiene que ver con las enormes oportunidades de progreso que los nuevos escenarios traen consigo, y con el insustituible rol de liderazgo que el sector público debe asumir para aprovecharlas, y para asumir todos estos cambios es necesario un modelo adecuado de gobernanza (Longo, 2019).

La Recomendación sobre Liderazgo y Capacidad en la Función Pública, adoptada el 17 de enero de 2019 por el Consejo de la Organización para la Cooperación y el Desarrollo Económicos (OCDE) a propuesta del Comité de Gobernanza Pública, destaca que una función pública profesional, competente y eficaz es un factor fundamental para fomentar la confianza en los ciudadanos en las instituciones públicas y cómo los servidores públicos y los sistemas utilizados para su gestión son un componente esencial de la gobernanza pública, que repercute directamente en la calidad de los procesos democráticos y en la capacidad de gobierno para promover y proteger el bienestar de los ciudadanos y generar y mantener un crecimiento económico inclusivo; reconociendo que la función pública se enfrenta a nuevos retos frente a quienes deben estar facultados y capacitados para responder de manera eficaz, en particular mediante la innovación y una interpretación más importante de las cuentas, al tiempo que se mantienen estables y fiables en la prestación de servicios de manera justa y oportuna y sobre la base de los principios de la buena gobernanza.

En el caso del empleo público local, y sin perjuicio de compartir una problemática columna vertebral con el empleo público de los demás niveles de gobierno, debemos advertir que presenta una serie de características muy marcadas por la excesiva temporalidad del mismo, la indefinición por la indebida gestión y la ausencia de planificación, la inexistencia de instrumentos de ordenación de recursos humanos adecuadamente configurados, capturas políticas y sindicales, aspectos todos ellos sobre los que, por su complejidad y por no formar parte de los objetivos fijados en el presente trabajo, no profundizaremos. En este análisis nos centraremos en el escenario que para el nivel de gobierno y administración local se abre en la actualidad, con la llegada de la cuarta revolución industrial, su impacto en la gestión, la digitalización y la automatización de procesos y cómo ese escenario condiciona el empleo público local. Porque será preciso contar con empleados públicos capacitados en dichas líneas de competencias profesionales, debiendo abordar la reforma del modelo de selección, provisión y carrera profesional, reforma que, como veremos, no pasa (únicamente) por un nuevo marco legislativo, sino por la valentía de adoptar decisiones diferentes a las tradicionales con una visión estratégica del empleado público como vector clave en este proceso de transformación de la administración.

Para ello se pondrá el acento en el análisis del nivel de gobierno y administración local desde la exposición de las peculiaridades que, frente a los niveles de Estado y CC.AA presenta, peculiaridades profundamente marcadas por la dimensión de la planta local. Y tras realizar una aproximación al marco legal y a los aspectos organizativos en la gestión de personas, abordaremos ese futuro del empleo público local, desde la óptica de la dimensión digital de la gestión pública, examinando el concepto de las competencias profesionales que se requieren para una adecuada prestación de servicios públicos locales y garantía de derechos de la ciudadanía ante la administración más próxima. Para ello el despiece de las competencias profesionales será segmentado en dos ejes que forman parte del mismo ecosistema: competencias digitales y competencias de soft law. Para cerrar, y tras una breve recapitulación, realizaremos una sistematización sobre las inaplazables decisiones que el mundo local debe tomar si no quiere prolongar la, por el momento, solo anunciada, obsolescencia del empleo público local.

\section{LAS PECULIARIDADES DEL MUNDO LOCAL Y SU PROYECCIÓN EN EL MODELO DE EMPLEO PÚBLICO}

Los cambios en el modelo de gestión local requieren también cambios en el modelo de empleo público, pues la prestación de nuevos servicios y la reconfiguración de las entidades locales en el momento actual, caracterizada por la versatilidad, diversidad y especialización presenta notables dificultades en relación a los niveles de gobierno estatal y autonómico, tal y como examinaremos a continuación (Campos et al., 2017).

\subsection{El dimensionamiento de la planta local como factor limitativo del cambio}

En un escenario tan complejo como el surgido tras la declaración de la pandemia por el COVID-19, los responsables de las entidades públicas que no estaban preparadas para el funcionamiento electrónico, han tenido que asumir una realidad íntegramente electrónica, aceptar el teletrabajo y las relaciones electrónicas 
interadministrativas, y poner sobre la mesa la necesidad de adecuar las competencias profesionales de los empleados públicos a un entorno digital. A pesar de existir un entorno normativo íntegramente digital en vigor desde octubre del año 2016, conformado por la Ley 39/2015, de 1 de octubre, de Procedimiento Administrativo Común de las Administraciones Públicas (LPAC) y Ley 40/2015, de 1 de octubre, de Régimen Jurídico del Sector Público (LRJSP), ha tenido que ser la situación generada a raíz del COVID-19 y su proyección en el empleo público la que ha generado el sentido de urgencia en la transformación digital y en el empleo público ${ }^{1}$.

Una mirada al empleo público local en los últimos 40 años permite observar el impacto de la crisis en el empleo público local y, en particular, las medidas de recorte adoptadas durante el período de crisis, se pone de manifiesto con el dato evolutivo del momento en el que el empleo público local presentó su nivel histórico más elevado, en el año 2011, momento en el que alcanzaba casi un escenario de 672.000 personas prestando servicios para la Administración local. Tras el progresivo descenso, producido no tanto por la crisis como por las citadas medidas, se observa que en el año 2019 se ha recuperado casi la totalidad de puestos (Esteban, 2019).

Según los últimos datos resultantes del boletín estadístico del personal al servicio de las Administraciones Públicas 2019, el personal al servicio de la administración local presenta los siguientes datos:

tABLA 1. PERSONAL AL SERVICIO de LA ADMinistración Local (2019)

\begin{tabular}{lrr}
\hline \multicolumn{1}{c}{ Tipo de personal } & Efectivos & \multicolumn{1}{c}{ Porcentaje } \\
\hline Funcionarios con Habilitación de Carácter Nacional & 5.171 & $0,91 \%$ \\
\hline Resto de personal & 565.648 & $99,09 \%$ \\
\hline TOTAL & 570.819 & $100 \%$ \\
\hline
\end{tabular}

Fuente: Boletín estadístico del personal al servicio de las Administraciones Públicas. Ministerio de Política Territorial y Administraciones Públicas.

La configuración de la planta local exige, desde el punto de vista de la gestión de personas diferenciar claramente dos niveles: por una parte, el de los más de seis mil ochocientos municipios con población inferior a cinco mil habitantes y, por otra, la de los mil trescientos que superan ese umbral. La diferente dimensión de unos y otros presenta problemáticas distintas y, en consecuencia, soluciones diversas. Como expondremos, respecto a los primeros debe reclamarse la acción de la asistencia y cooperación técnica por los gobiernos locales intermedios en el primer caso - diputaciones, cabildos y consejos insulares-, en tanto, que en el caso de las ciudades, la responsabilidad será de sus equipos de gobierno, adecuando sus estructuras y funcionamiento a esta nueva política de recursos humanos (Cuenca, 2019).

Según el Instituto Nacional de Estadística (INE), en 2019 el $72 \%$ de la población en España ocupaba el $1 \%$ de todo el territorio y el $90 \%$ de los residentes en España residía en el $12 \%$ del territorio. Según el INE (2020) en 2019, más del $60 \%$ de los ayuntamientos en España tenía menos de 1.000 habitantes, y en ellos vivía el 3,1\% de la población. De los 8.124 municipios españoles, 2.627 (32,3\%) tienen entre 101 y 500 habitantes; de ellos 1.360 (16,7\%) tienen 100 habitantes o menos, es decir, el $90 \%$ de la población en España vive en el $30 \%$ del territorio (Losa y Vaquero, 2020). La realidad nos muestra como únicamente 63 municipios españoles tienen más de 100.000 habitantes, el $40 \%$ de toda la población española, datos que evidencian las dificultades de disponer de sistemas uniformes en la gestión de personas.

En este sentido, y a efectos valorativos del modelo de empleo público local de futuro, puede afirmarse que uno de los condicionantes que producen mayor impacto en el mundo local es la dimensión de su planta, impacto que se produce básicamente en tres planos: disponibilidad de recursos, ineficiencias en la financia-

\footnotetext{
1 En el ámbito local, por ejemplo, a pesar de la ya antigua demanda para permitir la asistencia en remoto a las sesiones de los órganos colegiados de gobierno, voto incluido, ha tenido que ser el COVID-19 el motivo que justificase una reforma legal que lo permitiese, y así la previsión de las sesiones telemáticas por los órganos colegiados de gobierno local se ha incluido expresamente en el articulado de la Ley 7/1985, de 2 de abril, Reguladora de las Bases de Régimen Local (LRBRL) mediante la adición de un apartado tercero al artículo 46 por el Real Decreto-Ley 11/2020, de 31 de marzo, por el que se adoptan medidas urgentes complementarias en el ámbito social y económico para hacer frente al COVID-19.
} 
ción y calidad en los servicios. En este sentido, debe tenerse en cuenta que el importante declive demográfico ha convertido a muchos municipios en minúsculos núcleos de población, con cada vez menos población y más personas de edad avanzada, que mantienen su condición administrativa, pero se ven incapaces, por no contar con suficientes medios personales y materiales, de autogestionar sus intereses y las demandas de la ciudadanía.

\subsection{Las entidades locales como prestadoras de servicios básicos a la ciudadanía}

Para abordar el modelo de empleo público local es preciso plantear, en primer lugar, el papel que corresponde a las entidades locales, que distan mucho del que desempeñaban cuando se fraguó su primera regulación a mediados de los años 80 . Si bien recogía ya unas amplias competencias para la intervención en la vida de sus ciudadanos, la configuración de los servicios públicos que se presta desde el mundo local ha sufrido una profunda transformación en cuanto a la forma y al fondo. A la prestación de servicios municipales de carácter básico, conforme a lo establecido en el artículo 26 LRBRL, debemos añadir los inéditos escenarios derivados de la introducción de nuevas tecnologías, no sólo la administración electrónica, sino también el open data, el big data o el blockchain, y nuevos modelos de gestión demandados por una sociedad cada vez más activa y conocedora de sus derechos.

Las entidades locales se ven abocadas a sumarse a la transformación que si bien se denomina digital, va mucho más allá, pues se trata, en realidad, de la transformación del modelo de administración pública. Un simple vistazo a los que el artículo 26 LRBRL define como servicios municipales básicos en función de la escala poblacional es suficiente para calibrar la diferente dimensión, y en consecuencia, coste que tienen en la actualidad, así como las capacidades con las que debe contar el personal al que corresponde su prestación, en el marco de las amplias competencias conferidas a las entidades locales vía artículo 25 LRBRL, y, sin perjuicio de lo que establezca la normativa autonómica dictada en la materia.

Sin olvidarnos del impacto que la externalización de servicios públicos puede tener en el dimensionamiento de los recursos humanos que puedan necesitar las entidades locales en el ejercicio de sus competencias, pues ha presentado tradicionalmente notables ventajas en términos de flexibilidad en relación con el modelo de empleo público, dada la imposibilidad de contratar nuevos empleados públicos, por el elevado coste de los empleados públicos o como consecuencia de las rigideces del modelo de gestión, alejándose de los criterios que deben motivar esta decisión para la mejora de la calidad y la eficiencia de los servicios públicos en términos de lógica contractual, y convirtiéndose en un cauce para resolver problemas derivados de una mala organización y una deficiente gestión de recursos humanos (García et al, 2007).

La importancia del factor humano en una administración tan próxima al ciudadano y que atiende con inmediatez gran número de servicios básicos de prestación obligatoria, exige ofrecer herramientas ágiles y flexibles, pero también eficaces para garantizar esas prestaciones. Pensemos en la naturaleza de los servicios que se prestan desde el mundo local, y su impacto en la vida de la ciudadanía, como servicios sociales, recogida y tratamiento de residuos sólidos urbanos, tráfico y seguridad ciudadana, ciclo integral del agua, servicios de urbanismo, etc. que, además, presentan cada vez mayores niveles de complejidad. Para la prestación en términos de calidad y alineados con los Objetivos del Desarrollo Sostenible (ODS) es necesaria una organización de recursos personales que conjugue un marco legal claro y de instrumentos de gestión que permitan un desarrollo flexible que haga frente a una demanda sostenida y elástica, y integrando, al tiempo, los principios de legalidad con los de economía y eficiencia (Campos et al., 2017).

A la hora de evaluar el impacto de la digitalización y la automatización del mundo local no debe llevarnos a engaño la temprana tendencia de las ciudades por las tecnologías inteligentes (Smart) y la apuesta por las conocidas como smart cities, las ciudades inteligentes, pensando que el ámbito local se encuentra en un nivel más avanzado en relación con el despliegue del nuevo modelo de administración. En muchos casos, esta smartificación se ha visto reducida a sensores instalados en las papeleras, farolas, semáforos y, en las calles, sin saber cómo gestionar la información que dichos dispositivos ofrecen en el marco de big data y la inteligencia artificial, y sin optimizar, en consecuencia, las oportunidades y posibilidades que de ello se derivan (Ramió, 2018).

\subsection{Marco normativo de aplicación al empleo público local}

La aprobación en el año 2007 del Estatuto Básico del Empleado Público, Ley 7/2007, de 14 de mayo, en la actualidad, Texto Refundido, aprobado por Real Decreto Legislativo 5/2015, de 30 de octubre, (en adelan- 
te TREBEP) intentaba marcar un nuevo modelo de empleo público. A pesar de tratarse de un texto novedoso que incorporaba en su día diversas herramientas para la modernización del modelo de empleo público, bien sea por el peso de la rutina o de los intereses creados o porque no se ha considerado cuestión urgente avanzar en las reformas del empleo público, o por las dudas sobre qué hacer y sobre las consecuencias de los cambios que aquella legislación básica propicia, «la situación normativa es un EBEP apenas desarrollado y peor aplicado» (Sánchez, 2012).

En cuanto al marco legal aplicable al empleo público local, la LRBRL contempla en su artículo 92, que los funcionarios al servicio de la Administración local se rigen, en lo no dispuesto en la misma por el TREBEP, por la restante legislación del Estado en materia de función pública, así como por la legislación de las Comunidades Autónomas, en los términos del artículo 149.1.18.a) de la Constitución Española (CE). Este marco legal se completa con lo dispuesto en el Real Decreto Legislativo 781/1986, de 18 de abril, por el que se aprueba el Texto Refundido de Disposiciones vigentes en materia de Régimen Local (TRRL) y las especialidades en la regulación de los funcionarios de administración local con habilitación de carácter nacional que luego se verán.

El empleo público local no ha sido objeto de atención preferente en la reforma efectuada en el año 2013, por la Ley 27/2013, de 30 de diciembre, de Racionalización y Sostenibilidad de la Administración Local (LRSAL), pero sí contenía algunas modificaciones que afectaban al empleo público local, demostrando una tendencia a la funcionarización, a una cierta limitación del personal de libre nombramiento político y a la centralización del régimen de los funcionarios con habilitación de carácter nacional, en garantía de la mayor independencia de los mismos, en particular, en lo relativo a la Intervención (Sánchez, 2014). Tampoco el legislador autonómico se ha preocupado, con carácter general, en abordar nuevos enfoques para las entidades locales en cuanto a la planificación, dirección y evaluación de personas, como lo demuestra la Ley 2/2015, de 29 de abril, de Empleo Público Local de Galicia.

Se demuestra así el escaso interés tanto del legislador estatal como de los autonómicos por abordar las especificidades propias de las administraciones locales en general, y de su personal en particular. Así, no deja de resultar desolador que la regulación de los recursos humanos de un Ayuntamiento de 5.000 habitantes, con no más de 40 efectivos, se someta a la misma disciplina que una administración que gestiona más de dos millones de habitantes y cuenta con miles de efectivos. Ni la selección de personal, ni la reserva de plazas a personas con discapacidad, ni la movilidad de su personal, ni la carrera profesional o los sistemas de ordenación y estructuración del personal, pueden ser los mismos.

\section{APROXIMACIÓN A LAS PATOLOGÍAS EN LA DEFINICIÓN DEL MODELO DE GESTIÓN DE PERSONAS}

El personal que presta sus servicios en las entidades locales presenta una serie de patologías muy comunes al conjunto de las que se identifican en general para el personal al servicio de las diferentes administraciones públicas, que si bien no es posible abordar en toda su dimensión, sí enunciaremos para ofrecer una visión global de diagnóstico.

\subsection{Disfunciones comunes en la gestión de personas}

\section{La falta de gestión del relevo generacional}

En estos momentos las administraciones públicas se caracterizan por un notable envejecimiento de unas plantillas que no han ido incorporando un sistema de renovación del capital humano, y, en consecuencia, la inexistencia de mecanismos de transferencia del conocimiento que impedirá un correcto relevo generacional. Este escenario presenta dos serios riesgos: por un lado, la falta de servidores públicos conectados generacionalmente con los cambios tecnológicos y sociales; y, por otro, la pérdida del know-how, de la experiencia acumulada.

Parece así que es una urgencia contemporánea el abordar el envejecimiento y la renovación generacional de los empleados públicos, denostando las críticas a los empleados de mayor edad, únicamente en atención a dicho dato, por considerar que ya no son válidos para el nuevo modelo. Esta situación no se predica en exclusiva del sector público, pues en general se habla de la fuga de cerebros de entre los más jóvenes, hasta 1,1 millón de jóvenes entre 16 y 35 años emigró entre los años, 2012-2018, lo que no hace más que empeorar el balance generacional, pero nadie habla de la fuga de talento de los mayores de 55 años, en muchos casos como consecuencia de su descarte por edad (Rosillo, 2019). 


\section{Inexistencia de carrera profesional}

EI TREBEP dedica su Capítulo II, del Título III a la regulación de concepto, principios y modalidades de la carrera profesional de los funcionarios de carrera, disponiendo que la carrera profesional se configura como el conjunto ordenado de oportunidades de ascenso y expectativas de progreso profesional conforme a los principios de igualdad, mérito y capacidad, para garantizar dicho derecho las Administraciones Públicas promoverán la actualización y perfeccionamiento de la cualificación profesional de sus funcionarios de carrera.

Sin embargo, la carrera administrativa no está respondiendo a su verdadera finalidad sino que se ha utilizado como puente para generar una vía de incremento salarial, y como no existe implantada en España una auténtica carrera administrativa de carácter horizontal se produce en el sistema una enorme presión por crear más estructura (puestos de jefatura con niveles altos) de la objetivamente necesaria, presión que en el ámbito local se ejerce con mayor facilidad por la proximidad que permite capturas sindicales y/o políticas. La carrera profesional en los Ayuntamientos pequeños sólo puede realizarse a través de la movilidad interadministrativa que, a pesar de los tímidos intentos del legislador, todavía está enfocada muy restrictivamente, su instrumentación necesita en todo caso de un convenio o que otras administraciones puedan crear puestos abiertos a su cobertura por empleados de otras administraciones atendiendo a criterios de reciprocidad, con algunos ejemplos como los previstos en la normativa autonómica gallega, en relación con el ámbito local.

\section{Ausencia de planificación}

Las urgencias de la gestión crítica es una (frecuente) disfunción en el ámbito local, por lo que la planificación no es una de las características generalizadas en este nivel de gobierno y administración, disfunción que se extiende al ámbito del empleo público local donde se observa una falta de una estructura organizativa o la existencia de una estructura muy antigua que ha quedado totalmente obsoleta y no se adapta a la realidad. No cabe duda de que el cambio pasa por las personas que forman parte de la organización, pero si no se organiza a esas personas mucho esfuerzo puede perderse (Povedano, 2019).

Las relaciones de puestos de trabajo (RPT), en las entidades en las que existen, ha servido, en muchos casos, para la acomodación de los puestos de trabajo ya existentes que fueron creándose sin mayor planificación que las conveniencias políticas y administrativas del momento, además aunque resulta obligatoria su elaboración, parecen responder a una idea formalista y estática por cuanto no se impone ninguna obligación de revisión periódica lo que resta del dinamismo que requieren para la motivación del personal y la adecuación continua de los recursos humanos y de las funciones que desempeñan a la realidad.

\subsection{La inexistente dirección pública profesional y el papel de los funcionarios de habilitación nacional}

La reflexión de que será a los responsables máximos de las entidades locales planificar el despliegue tecnológico en las mismas y su impacto en el empleo público, nos sitúa ante una realidad marcada por la ausencia de profesionalidad en los niveles de dirección pública local. No es una característica en exclusiva del mundo local, pero sí presenta especiales aristas por la proximidad que caracteriza a los niveles de gobierno y administración local y la fuerte influencia que la demanda ciudadana puede ejercer en términos de dinámicas electorales y capturas de gestión. La transformación de las dinámicas del empleo público exige el ejercicio de un fuerte liderazgo, que, en el ámbito local, presenta una dualidad clara, por un lado el liderazgo político que corresponde a los representantes políticos, de naturaleza electa, y, por otro, el liderazgo directivo en el plano administrativo y que, ante la ausencia de un nivel directivo propio en la función pública local, corresponde, en la mayoría de las ocasiones, de facto, a los Funcionarios de Administración Local con Habilitación de Carácter Nacional (FHN). Y ello es así porque este cuerpo de funcionarios constituyen la columna vertebral que, desde el punto de vista de la dirección, se puede encontrar en una planta local tan asimétrica como la nuestra, figura común a todos los municipios y dotados de un conocimiento transversal y unas competencias profesionales que les convierten en el eje fundamental de la transformación.

EI EBEP abría un horizonte de esperanza en cuanto a la configuración de la dirección pública profesional al contemplar en su artículo 13 la figura de la dirección pública profesional. Sin embargo, a pesar del tiempo transcurrido, más de 13 años desde la aprobación del EBEP, el desarrollo de una dirección pública profesional sigue siendo una tarea pendiente, encontrando únicamente algunos desarrollos autonómicos, y, 
en el ámbito local, la creación de una categoría que podríamos calificar de híbrida entre la dirección pública profesional y la política tras la reforma de 2003. Debemos recordar que en relación con los Municipios de gran población se creaba una estructura directiva, en su artículo 130 LRBRL, introduciendo, por primera vez, la noción de órganos directivos en el ámbito local, tras distinguir entre órganos superiores y directivos.

Los intentos de regular la función directiva en la Administración local son paralelos a los de la legislación básica de régimen funcionarial, si bien adolecen de una aproximación parcial y compleja, en gran medida, precisamente, por la dificultad de deslindar la función directiva en la Administración local respecto a las funciones reservadas a los funcionarios con habilitación de carácter nacional (Fuentetaja, 2015). Sobre las posibilidades de regulación y desarrollo del estatuto del directivo local por las propias entidades locales se pronunciaba el Tribunal Supremo por la STS de 17 de diciembre de 2019 (rec. 2145/2017) dando respuesta a la cuestión de interés casacional, consistente en determinar «Si entra dentro de las competencias de los entes locales y, en particular, de las Diputaciones Provinciales la regulación de su personal directivo» y concluye fijando doctrina casacional en el sentido de que «el artículo 13 del Estatuto Básico del Empleado Público atribuye su desarrollo al Gobierno y a las Comunidades Autónomas».

Como se apuntaba, dentro del marco organizativo del empleo público local se encuentra una peculiaridad derivada de la existencia de categoría sui generis, los FHN. El rediseño y la reconfiguración del perfil de los FHN, pasando de ser órganos de control de legalidad y fiscalización a pilares del nuevo modelo de administración, nace, del proceso de transformación que está experimentando la propia administración en su transición al s. XXI y en el cual adquiere un protagonismo muy relevante el papel de las nuevas tecnologías, para alcanzar una administración innovadora, transparente, abierta, social. La modernización de este cuerpo se produjo con la aprobación del Real Decreto 128/20118, de 17 de marzo, por el que se regula el régimen jurídico de los funcionarios de Administración Local con habilitación de carácter nacional que, si bien se aprobaba, en mi opinión, sin aprovechar todas las oportunidades que el marco normativo existente y la configuración que la sociedad exige de una administración abierta, transparente, ágil y centrada en el ciudadano, se puede negar la mejora que, en muchos aspectos, se produce, en particular, en cuanto al refuerzo de las funciones reservadas a los FHN, que se reencuentran con funciones centrales en el nuevo modelo de administración pública, electrónica y transparente.

\section{LOS RETOS DEL EMPLEO PÚBLICO LOCAL EN EL S. XXI}

La condición necesaria, aunque no suficiente, para disponer de empleados públicos alineados con las necesidades de futuro del mundo local se deriva, en gran medida, de la política y la gestión de la selección. Y una vez se ha logrado introducir en una institución pública el talento profesional, de lo que se trata es de mantenerlo e incrementarlo, y ahí es cuando entran en juego otros elementos básicos de un modelo de gestión de recursos humanos como, entre otros, la formación, la carrera administrativa y la evaluación del desempeño (Ramió, 2017a).

\subsection{Enfocando necesidades del empleo público local desde la obsolescencia del modelo actual}

Los apuntes realizados en relación con este tema adquieren todavía mayores dimensiones en el ámbito de la administración local, a las que el dimensionamiento de la planta local, la escasez de recursos y la (con) fusión entre los niveles de gobierno y administración la convierten en rehén de prácticas clientelares, sin que ni tan siquiera podamos culpar de la endémica situación en la que se hayan únicamente al modelo de selección vía oposición tradicional. La problemática apunta a cómo «las élites de la mayoría de las sociedades tienden a recurrir a redes de familiares y amigos», sobre la base de la selección por parentesco y altruismo recíproco. Hunde sus raíces en el spoil system, explicado por el presidente de EE.UU, Jefferson, sobre la base de que los puestos públicos son sencillos, y por ello cualquier ciudadano, y quién mejor que aquéllos de su círculo que le ayuden a implementar su programa electoral, con mínima cultura y sentido común puede hacerlo (Fukuyama, 2016).

Aunque el marco legal en materia de empleo público está obsoleto y necesita una profunda revisión, nada impide a las entidades locales adoptar medidas de modernización de los procesos selectivos que permitan alinear la captación de talento con las necesidades que presenta el mundo local. Con carácter previo abordaremos una cuestión colateral pero muy relevante cómo es la relativa al órgano de selección, su configuración y composición, que juega también un papel determinante, máxime en el ámbito local de nivel 
medio y pequeño, en el cual el principio de proximidad, tan positivo en determinados escenarios, el recurso al personal de la propia entidad, normalmente vecinos de la propia localidad, con vínculos sociales, familiares, políticos o económicos, así como la proximidad del órgano político y en consecuencia a la presión que éste pueda ejercer, supone un riesgo para la integridad del proceso selectivo, por lo que sería recomendable contar con personal ajeno a la misma.

De hecho, esta medida está ya prevista en algunas leyes autonómicas para la selección de los policías locales o, con carácter general (Fondevila, 2008), como, por ejemplo, La Ley 5/2010, de 11 de junio, de Autonomía Local de Andalucía acoge esta posibilidad a través de la Diputación Provincial, al contemplar, en su artículo 12.1, entre lo deberes de asistencia técnica de la provincia al municipio, la selección del personal de los municipios de su ámbito territorial.

\subsection{Seleccionando personal del s. XXI con métodos del s. XX: cómo avanzar}

El TRRL dispone, en su artículo, 133 que el procedimiento de selección de los funcionarios de Administración Local se ajustará a la legislación básica del Estado sobre función pública, y se establecerá teniendo en cuenta la conexión entre el tipo de pruebas a superar y la adecuación a los puestos de trabajo que se hayan de desempeñar, incluyendo a tal efecto las pruebas prácticas que sean precisas. Este mandato debe completarse con lo establecido en el Real Decreto 896/1991, de 7 de junio, por el que se establecen las reglas básicas y los programas mínimos a que debe ajustarse el procedimiento de selección de los funcionarios de Administración Local ${ }^{2}$, normas que han quedado absolutamente obsoletas y desactualizadas.

Por su parte, en el artículo 61 TREBEP el legislador básico establece un mandato que resulta fundamental a efectos de reforzar las propuestas de este trabajo en cuanto a la definición de un modelo de empleo público local de futuro y la necesidad de abordar la captación del talento necesario a través de sistemas menos arcaicos, cuando señala que los procedimientos de selección cuidarán especialmente la conexión entre el tipo de pruebas a superar y la adecuación al desempeño de las tareas de los puestos de trabajo convocados, incluyendo, en su caso, las pruebas prácticas que sean precisas. Porque frente a las resistencias formalistas al cambio, las voces que reclaman una reforma en el sistema de acceso al empleo público actual no pretenden una ruptura con los principios de mérito y capacidad establecidos en el artículo $103 \mathrm{CE}$, sino un cambio en el modelo caduco de la oposición de mediados del SXX como mero ejercicio memorístico y de repetición como única vía de acceso al empleo público, con independencia del tipo de puesto a desempeñar, sin evaluar competencias y capacidades.

Una mirada a nuestro alrededor permite comprobar que existen en la actualidad algunos modelos de selección de empleados públicos que optan por otros mecanismos para proveer a las Administraciones del que será su personal, como en el caso de Reino Unido, que cuenta con un programa orientado a captar talento de las universidades mediante la realización de unas prácticas retribuidas en el periodo estival, en la que los estudiantes tendrán ocasión de conocer el funcionamiento real de una Administración Pública ${ }^{3}$. La participación en este programa con una valoración positiva permite el acceso al Fast Pass como vía prioritaria para llegar a la fase final del proceso de selección, además de un curso de preparación avanzado para superar el Civil Service Fast Stream ${ }^{4}$. En Francia se ha llevado a cabo también un proceso de modernización del empleo público, donde se puede destacar el esfuerzo de concreción del proceso de selección de personal laboral, y el intento de dar mayor clarificación a los regímenes de contratación temporal/indefinido (Boto, 2016).

\subsection{El aprendizaje contínuo en tiempos líquidos: practicando el reskilling}

La formación de los empleados públicos no sólo debe ser concebida como una herramienta vinculada al proceso de ingreso en la administración, sino como un proceso continuo a lo largo de toda la carrera administrativa. Se trata de un derecho contemplado en el TREBEP, pero que constituye también un deber, máxime en un entorno tan volátil como el actual, en el aprendizaje que se configura como un derecho-deber y para la adecuada configuración del modelo de empleo y sobre todo, a efectos de garantizar la adecuación de conocimientos y destrezas del puesto en cada momento dada su «liquidez» (Bauman, 2002), que permita

\footnotetext{
2 Recoge el acceso al empleo público local, con carácter general, a través del sistema de oposición, salvo que, por la naturaleza de las plazas o de las funciones a desempeñar, sea más adecuada la utilización del sistema de concurso-oposición o concurso.

3 Summer Diversity Internship Programme.

4 https://www.faststream.gov.uk/.
} 
el desempeño del mismo para garantizar la calidad de los servicios públicos y la igualdad de derechos de los ciudadanos.

En este sentido resulta preciso prestar especial referencia a la excesiva atención a la formación jurídica de los empleados públicos, descuidando la adquisición de otros conocimientos, que hoy podríamos incluir en el ámbito de las competencias, señalando el profesor Royo-Villanueva (1950) expresamente que no sólo deberían crearse juristas sino «administradores», pues el mero conocimiento de las leyes no habilita para la buena administración, siendo necesario disponer de mayor información y habilidades para ofrecer la solución acertada, la más adecuada para la finalidad de responder al interés general.

Jiménez (2019) apunta especialmente a cómo son precisamente las profesiones jurídicas en las Administraciones Públicas, en cuanto que buena parte de las tareas que realizan hoy en día serán automatizadas a medio plazo, las que deben establecer procedimientos de revisión y análisis sobre su necesidad, que, de conformarse, exigirá una nueva configuración más allá del contenido puramente jurídico, pues será necesario no sólo comprobar que cuentan con un elevado conocimiento y destrezas de competencias digitales, y garantizar que acrediten actitudes y aptitudes para desarrollar competencias imprescindibles en su labor futura: creatividad, iniciativa, resiliencia y adaptación al cambio, empatía, trabajo en equipo y pensamiento crítico.

El concepto tradicional de formación debe evolucionar, para adaptarse a los cambios profundos que supone la sociedad del conocimiento, «Más que proporcionar formación debe facilitar experiencias de aprendizaje que permitan acceder, crear y compartir conocimiento no sólo hacía dentro de la organización sino también hacia la ciudadanía ofreciendo productos y servicios con valor público». Es necesario proporcionar condiciones para la adquisición de competencias horizontales comunes a todas las personas que trabajan en las administraciones públicas, pero también es necesario trabajar una serie de competencias vinculadas a los distintos puestos de trabajo (Seisdedos, 2019) y para ello es preciso llevar a cabo un análisis de los puestos que, en la mayor parte de las entidades locales, no se lleva a cabo y dotar de capacidad de adaptación a nuevos puestos de trabajo necesarios para prestar servicios públicos que aún están por crear y diseñar (De la Nuez, 2018).

\section{COMPETENCIAS NECESARIAS EN LA DEFINICIÓN DE LOS PERFILES PROFESIONALES DEL MUNDO LOCAL}

La gestión de los recursos humanos en el ámbito local presenta importantes retos ante el gran cambio en el que se encuentra el mundo actual y que ha sufrido una relevante aceleración por el efecto del COVID-19, cambios que se centrarán en el futuro en la nueva organización del trabajo y que vendrán de la mano de la robótica y de la inteligencia artificial. Para asumir este nuevo entorno digital y tecnológico la capacitación de los empleados públicos y la dotación de las competencias profesionales adaptadas a la sociedad del s. XXI la clave pasa por configurar un modelo de capital humano basado en dos tipos de competencias. Por una parte, las competencias digitales, que permiten conocer las potencialidades de la tecnología y su aplicación en la gestión pública, debilitando, también, esa aversión al riesgo que impide en muchos casos su pleno despliegue. Y, por otro, las competencias blandas, las soft skills, que facilitarán que el valor añadido de talento humano pueda desarrollarse en aquellos ámbitos donde las máquinas no llegan, en la creatividad, asertividad, resiliencia, en capacidades que convergen en la inteligencia emocional que fomentará la necesaria adaptabilidad de los empleados públicos y responsables directivos y políticos.

Si se trata de un planteamiento complejo en el sector público, todavía presenta mayores dificultades en el ámbito local, tan intermediado por los condicionamientos expuestos, en cuanto a dimensionamiento y confluencia de intereses políticos, funcionariales y sindicales en un entorno de máxima proximidad y las dificultades apuntadas en relación con el dimensionamiento de la planta local y la inherente falta de recursos.

\subsection{Competencias digitales: articulando las bases de la evolución tecnológica}

La llegada de la cuarta revolución industrial a las administraciones públicas significa la transición hacia una gobernanza inteligente mediada por algoritmos, que implica tecnologías que requieren una interacción continua y el aprendizaje constante con los seres humanos (Margetts y Dorobantu, 2019), por lo que la interacción de la IA con los empleados públicos será fundamental, y la dotación de un currículo profesional de inteligencia emocional, de soft skills para éstos resultará clave para asumir los retos de futuro, tan marcados 
por la incertidumbre. Por ello, ante una sociedad hiperconectada y expuesta a flujos masivos de información, es necesario dotar a los empleados públicos de las capacidades y competencias necesarias para la gestión de ese escenario, fomentando las capacidades creativas, atencionales y físicas (Ruiz del Corral, 2017).

Resulta básica la capacitación de los empleados públicos en las nuevas competencias digitales, una realidad en la que coinciden las administraciones públicas, que requiere impulsar la formación de empleados y empleadas públicas en la transformación digital, invertir en tecnologías de la información y mejorar las competencias digitales del personal. Lo primero que tendremos que hacer es ofrecer una definición de las competencias digitales. En este punto seguiremos la definición utilizada en DIGCOMP que proviene de la Recomendación 2006/962/CE sobre las competencias clave para el aprendizaje permanente, y dice lo siguiente: "La competencia digital entraña el uso seguro y crítico de las tecnologías de la sociedad de la información (TSI) para el trabajo, el ocio y la comunicación. Se sustenta en las competencias básicas en materia de TIC: el uso de ordenadores para obtener, evaluar, almacenar, producir, presentar e intercambiar información, y comunicarse y participar en redes de colaboración a través de Internet». No debemos confundir las competencias digitales con la simple utilización de herramientas tecnológicas, como un smartphone o un ordenador, sino que va más allá, orientándose a un uso creativo, crítico y seguro de las tecnologías de la información y la comunicación, con el conocimiento y control de las principales aplicaciones informáticas, el acceso a fuentes seguras y el conocimiento de los derechos y las libertades que asisten a las personas en el mundo digital (Campos, 2020).

El DigComp distribuye estas competencias en cinco áreas: información, comunicación y colaboración, creación de contenidos, seguridad y resolución de problemas. La última versión de este documento se adapta a los avances digitales, planteando cuestiones transversales como la seguridad y la resolución de problemas, y otras más habituales como la generación de contenidos, la interacción a través de herramientas digitales o la simple comunicación. Todas ellas incluyen competencias diferenciadas (un total de 21) que se definen a través de 8 niveles de aptitud, clasificación que permite a profesionales y usuarios identificar la forma de mejorar sus capacidades a la hora de manejar los dispositivos electrónicos.

La versión actual se ha denominado DigComp 2.1 y busca el desarrollo de los tres niveles iniciales de competencia, para dar paso a una descripción más detallada en 8 niveles de aptitud, con ejemplos de uso de cada uno de ellos. El objetivo es servir de apoyo a los profesionales interesados en la implementación de este marco de referencia. La descripción de cada nivel contiene conocimientos, habilidades y actitudes definidas por descriptores en cada nivel y en cada competencia.

- Área de competencia 1: Información y alfabetización digital.

- Área de competencia 2: Comunicación y colaboración online.

- Área de competencia 3: Creación de contenidos digitales.

- Área de competencia 4: Seguridad en la red.

- Área de competencia 5: Resolución de problemas.

En todo caso, debe tenerse en consideración que en las administraciones públicas existen múltiples escalas, subescalas, y no todos ellos necesitan las mismas competencias digitales, y aún así, dentro de las mismas plazas el destino a un puesto de trabajo o a otro determinará el nivel necesario, pero, en todo caso, los procesos selectivos deben valorar las posibilidades de los candidatos para utilizar las TIC en su futuro trabajo, máxime teniendo en cuenta lo establecido en el marco DIGCOMP. De ahí que no sólo sea importante la determinación de estas competencias en el proceso de acceso, sino que también será fundamental la adecuada definición de los puestos para determinar el nivel necesario en competencias digitales de forma proporcional a los cometidos a desarrollar, en aplicación del deber recogido en el artículo 54.8 TREBEP se encuentra mantener actualizada su formación y cualificación, con particular importancia de las competencias digitales de los niveles directivos de la Administración.

\subsection{Una breve reflexión sobre el teletrabajo en el mundo local y el puesto de trabajo $360^{\circ}$}

La situación generada por el Covid19 y la declaración del estado de alarma nos situaba ante un nuevo e inédito escenario de aislamiento social y protagonismo de la digitalización en el ámbito profesional. Y en ese contexto, adquiría una relevancia no deseada un tema que había sido orillado reiteradamente por los modelos organizativos del empleo, tanto públicos como privados, el teletrabajo o el trabajo a distancia.

A pesar de que, inicialmente, no se adoptó una previsión de carácter general sobre el teletrabajo en el conjunto de las administraciones públicas, tratándose de una cuestión organizativa, tanto en el ámbito esta- 
tal, como autonómico y local se fueron adoptando medidas para facilitar la continuidad del funcionamiento en régimen de teletrabajo, tomando como referencia en muchos casos, las cuestiones de riesgo sanitario y conciliación de la vida personal y familiar para su priorización.

Con posterioridad y ante la necesidad impulsar nuevas formas de organización y estructuración del trabajo de los empleados públicos para el mejor servicio a los intereses generales que tienen encomendado y ante la constatación de la necesidad de seguir avanzando en la adaptación de las administraciones a la administración digital, se aprobaba el Real Decreto-ley 29/2020, de 29 de septiembre, de medidas urgentes en materia de teletrabajo en las Administraciones Públicas y de recursos humanos en el Sistema Nacional de Salud para hacer frente a la crisis sanitaria ocasionada por el COVID-19.

La regulación, limitada a la incorporación de un nuevo precepto al TREBEP, el artículo 47 bis, exige su adecuación bien por las normativas autonómicas bien por las respectivas entidades locales. En este sentido, para el ámbito local puede reseñarse la aprobación del Reglamento por el que se regula la prestación de servicios en régimen de teletrabajo en la Diputación Provincial de Almería, que más allá de la pandemia y las especiales circunstancias generadas por el COVID-19, y se aprueba con vocación de permanencia y estabilidad dentro del haz de potestades de las Corporaciones Locales, en particular, la reglamentaria y de autoorganización, dictado al amparo del artículo 4.1 LRBRL.

En esta línea debe citarse la aprobación de la Estrategia España Digital 2025 que contempla un apartado específico relativo a la Transformación del Sector Público, donde desgrana una serie de objetivos específicos y un conjunto de medidas orientadas a la Administración pública data-driven, desde la relevancia del dato y su gobernanza para la personalización de los servicios públicos y en la que contempla un nuevo concepto «puesto de trabajo de nueva generación». Afirma que se potenciarán soluciones de puesto de trabajo, conectividad y colaboración de nueva generación que habiliten la movilidad y el trabajo no presencial de los empleados públicos. En dicho sentido llama la atención el reskilling de los empleados públicos para adaptarse a esta nueva manera de trabajo, en alusión al trabajo íntegramente digital y también a distancia. Y de la proposición a la acción, encomienda al Instituto Nacional de Administración Pública (INAP) para desarrollar un Plan de capacitación de los empleados públicos en las competencias digitales para esa adaptación.

Por su parte, la Estrategia Nacional de Inteligencia Artificial, en el marco de las líneas de actuación contempla en la línea 5.1 «Aprovechar los beneficios para la administración del uso de la IA, la incorporación de la IA en la administración pública para mejorar la eficiencia en la relación con los ciudadanos, industria, empresas, y la sociedad en general y eliminar cuellos de botella administrativos y para ello, fomentar el uso de IA en la Administración, desde el acceso a la función pública, la formación de los empleados públicos, hasta la definición de puestos de trabajo».

\subsection{Impacto de la Inteligencia Artificial y la robotización en el empleo público local}

¿Qué futuro nos espera? Responder a esta pregunta exige un cierto ejercicio de funambulismo pues en estos tiempos resulta muy difícil realizar cualquier predicción, pero para intentar tener ciertas certezas, las entidades locales, en el marco de sus políticas públicas de recursos humanos deberán formular las preguntas adecuadas para poder planificar las vacantes y siguiendo a Gorriti (2018) éstas serían:

- ¿Qué necesito crear?

- ¿Qué necesito rediseñar?

- ¿Qué necesito no reponer?

Podemos decir que la idea fuerza que debe presidir la interacción entre la IA y los empleados públicos es muy clara: «las personas deberán hacer cosas que las máquinas no puedan hacer» y la creatividad, la empatía y otras cualidades sólo se predican, al menos de momento, de los seres humanos, por lo que es precisa una revisión del modelo de unas administraciones públicas monopolizadas por la dimensión jurídica, para advertir los impactos de esta transformación digital y robótica pueden ser sencillamente extraordinarios (Jiménez, 2018). Quizás la cifra del $47 \%$ en destrucción de empleo como consecuencia de la automatización (Osborne et al., 2017) pueda ser un poco excesiva, pero no cabe duda que este proceso sí tendrá impacto en el empleo en general, y también en el empleo público, en particular. Según Hidalgo (2018) la probabilidad de automatización en las Administraciones Públicas alcanzaría un 44,8\%. Algunos puestos son susceptibles de automatizarse y probablemente se automatizarán, pero en la mayoría de los casos, serán algunas de las tareas que desempeñan las que serán objeto de automatización, siendo preciso proceder al rediseño 
de los puestos, a través de una adecuada gestión de vacantes.. En esa disyuntiva, sustitución o complementariedad, las tareas que no podrán ser automatizadas son aquéllas vinculadas a las las soft skills, el gran aporte de los empleados públicos, de hecho, como hemos visto, la caracterización de las tareas como rutinarias o vinculadas a la inteligencia, fuerza física o habilidades sociales y su peso relativo, serán las que determinarán la probabilidad de automatización de las tareas.

El especial dimensionamiento de las entidades locales las convierte en un ámbito en el que abunda el empleo no cualificado, auxiliares, administrativos, notificadores, conserjes, puestos de trabajo que, sin duda, se verán impactados en mayor medida por la automatización de procesos, de tal modo que la revisión de los procesos y su automatización hará que desaparezcan estas necesidades de personal ${ }^{5}$. Sin perjuicio de ello, también se extenderá a determinados ámbitos profesionales más cualificados, como contabilidad y auditoría, aunque probablemente el proceso sea mucho más lento de lo que auguran los diferentes pronósticos, en el caso de la administración y dado su carácter reactivo no cabe duda de que los impactos se producirán a menor velocidad, máxime en el ámbito local, donde la priorización de intereses particulares, corporativos y clientelares tienen mayor capacidad de maniobra para ralentizar, cuando no evitar, los cambios (Ramió, 2017b).

La reducción estimada en un $30 \%$ de los actuales puestos de trabajo, se vería parcialmente paliada por el incremento derivado de nuevos perfiles profesionales: a los actuales gestores tecnológicos habría que añadir personal especializado en gestión de la información y de la inteligencia artificial, desde analistas de big data hasta otros analistas de información, diseñadores y gestores de la robótica, controladores y evaluadores de los sistemas externalizados y, finalmente, otras profesiones que todavía son desconocidas. Estos nuevos colectivos profesionales podrían suponer el incremento de un $10 \%$ de efectivos de personal. Entre la reducción y el incremento el resultado final podría acercarse a una reducción del $50 \%$ del actual volumen de personal. Es decir, podríamos pasar en España de los 3,1 millones actuales de empleados públicos a un 1,5 millones (Ramió, 2017a).

Sobre cómo impactará la robotización y la automatización en el empleo público local, podemos resumir lo expuesto en torno a los siguientes ejes (Ramió, 2017b):

- La organización del trabajo cambiará. Al igual que en las precedentes revoluciones industriales, la cuarta revolución traerá consigo una profunda remodelación de la organización del trabajo, que impactará en tres niveles, destrucción, en el caso de la administración pública, básicamente en los niveles subalternos y auxiliares, sin perjuicio de la afectación a determinados puestos cualificados; transformación, rediseñando aquéllos puestos que permitan su adecuación y aparición de nuevos puestos 6 .

- El personal que permanezca al servicio de la administración pública en el futuro tendrá un perfil muy mayoritario de elevada cualificación, serán aquéllos que en atención a unos perfiles profesionales marcados no sólo por el conocimiento sino también por las competencias blandas puedan aportar mayor valor público.

- Urge abordar procesos de consolidación del empleo local y de la regularización de los millares de empleados locales en situación precaria. La gestión de los recursos humanos en el ámbito local presenta importantes retos ante el gran cambio que se avecina en el futuro en la nueva organización del trabajo y que va a venir de la mano de la robótica y de la inteligencia artificial.

\subsection{Dificultades en la introducción y evaluación de soft skills en el empleo público local}

Frente a la realidad descrita que nos plantea el elevado grado de automatización que se ha puesto en marcha y su imparable avance debemos tomar en consideración que el impacto en el empleo público no sólo se producirá en términos de desaparición sino que dicho impacto revertirá en una mayor flexibilidad del modelo, en cuanto los «burócratas», como tales, desaparecerán, ya que su labor diaria se concentra en la realización de tareas mecánicas y repetitivas, siendo por tanto la creatividad y la inteligencia

\footnotetext{
5 Pensemos en áreas de trabajo específicas del mundo local como es la gestión del empadronamiento y la emisión de certificados que ha sido objeto de Robot Process Automation (RPA) ya por numerosas entidades locales.

6 POVEDANO (2019) propone considerar «a extinguir» los puestos de: conserje, bedel, auxiliar administrativo, peón y crear puestos de relaciones públicas, protocolo y comunicaciones, técnico de administración electrónica, e-archivero, compliance público o analista de datos públicos.
} 
emocional factores clave del nuevo tiempo. Porque al margen de cuestiones de orden tecnológico, la aplicación de las tecnologías en ámbitos resistentes como el público, requiere no sólo de recursos tecnológicos sino también de competencias blandas tanto por los responsables políticos como administrativo valentía, creatividad y think out of the box, para proceder a la adopción de casos de uso que permitan ir introduciendo este tipo de innovaciones, y que, al tiempo se permita el desarrollo de la creatividad (Catalá y Cortés, 2019).

Según el documento "Habilidades, educación y empleo en América Latina (BID 2012)"; las habilidades se podrían agrupar en cognitivas y no cognitivas o socioemocionales. Las primeras estarían en la esfera de la cognición, y se vinculan al coeficiente intelectual, y también formarían parte del «saber académico» o área del conocimiento que incluye las matemáticas y el lenguaje. $Y$ habilidades socioemocionales serían parte del «área del comportamiento» y el énfasis fundamental es que pertenecen a los rasgos de personalidad (Gutiérrez y Matus, 2015). Abordar la incorporación de las soft skills al nuevo modelo de empleo público es una necesidad presente y que se agudiza con la evolución de la implantación de las tecnologías y la generalización de las técnicas de robotización e inteligencia artificial.

Uno de los mayores obstáculos que se presenta a la utilización de las soft skills en el acceso al empleo público puede advertirse con facilidad por su difícil encaje en el modelo actual anteriormente descrito, dada la intangibilidad de las mismas. El problema de la evaluación de este tipo de competencias, tradicionalmente se ha abordado desde tres perspectivas: la primera, mediante instrumentos basados en cuestionarios y autoinformes de los empleados que se someten a la evaluación, la segunda a través de medidas de evaluación de observadores externos, basados en cuestionarios cumplimentados por los propios compañeros o por el responsables y una tercera que comprendería medidas de habilidad o de ejecución frente a diversas tareas de carácter emocional que el interesado debe resolver (Pacheco y Berrocal, 2004).

En el ámbito local, dentro de la poca literatura específica, destaca una investigación sobre la inteligencia emocional como habilidad directiva en el contexto de la Administración Local en la Provincia de Córdoba (España), que, sin perjuicio de otras consideraciones, permite extraer las siguientes conclusiones (Pereda et al., 2018):

a) la influencia que los empleados públicos otorgan a las habilidades directivas sobre aspectos organizacionales es muy alta, como lo demuestra las medias obtenidas, todas, excepto una, por encima de 4, sobre una escala de Likert de cinco puntos;

b) resulta muy llamativo la gran influencia que los empleados públicos otorgan a las habilidades como responsable en la estrategia de mejora de la eficacia y eficiencia, así como en los resultados alcanzados por las organizaciones;

c) igualmente, la mejora en la motivación y satisfacción de los empleados es un aspecto muy valorado como un resultado muy destacable en el deseado despliegue de las habilidades por parte del personal directivo, fundamentalmente;

d) curiosamente, la única variable que se queda por debajo de 4, que aún siendo alta, es precisamente la influencia en la selección de los empleados públicos.

A pesar de la revolución que la utilización de estas competencias para la selección y captación del empleo pueda parecer, no se trata de un ámbito tan novedoso, pues podemos remontarnos a la China Imperial, en fechas tan tempranas como en el año 2200 a.c., donde ya se empleaba un sistema de exámenes para valorar y decidir si los funcionarios del gobierno eran aptos o no para el desempeño de sus funciones. Se trataba de un sistema que se configuraba con una periodicidad que era trienal y se servía de "pruebas» para evaluar las habilidades en música, tiro con arco, equitación y escritura o los conocimientos sobre los principios de Confucio, los ritos y las ceremonias, las leyes civiles, la agricultura, la geografía o la poesía. Se trataba de exámenes orales, más que escritos, que no sólo evaluaban lo que los candidatos decían, sus conocimientos, sino también cómo lo decían (Arribas, 2014)

\section{RECAPITULANDO EL ESTADO DE LA CUESTIÓN Y PERSPECTIVAS DE REFORMA}

Desde el punto de vista de la gestión pública, podríamos afirmar que nos encontramos ante un final de ciclo, cuyo inicio se sitúa en la revolución francesa y en la revolución industrial para poner fin con la revolución tecnológica y de la sociedad del aprendizaje, todavía pendiente de definición del nuevo orden económico y del nuevo modelo político e institucional, identificando 4 modelos de administración pública 
desde finales del S. XIX: modelo de patronazgo o clientelar, modelo burocrático, modelo gerencial y modelo de gobernanza. Si bien, en el caso de las entidades locales resulta necesario tomar en consideración las diferencias de nivel que presenta en relación con los niveles de gobierno y administración del Estado y de las Comunidades Autónomas, peculiaridades que condicionan, en gran medida, las posibilidades de contar con un único modelo de empleo público adecuado a las fuertes asimetrías del mundo local (Ramió, 2017a).

\subsection{Repensando el modelo desde el debate multilateral}

La reforma del modelo de empleo público se encuentra, en la actualidad, en el epicentro del debate público, académico y profesional, sobre la base de los factores que hemos estado examinando: el creciente envejecimiento de las plantillas, las dificultades de la administración para la retención del talento, la adecuación de estructuras y organización a los instrumentos legales, y las dificultades para adecuarse a las novedades derivadas del nuevo modelo de sociedad y las nuevas tecnologías.

La fuerte crisis que se iniciaba en el año 2008 tuvo también unos efectos devastadores sobre las unidades de recursos humanos del sector público y las personas que allí trabajan, afirmación que se extiende en grado máximo al ámbito local y como consecuencia, se ha producido una simple reposición, allí donde las limitaciones presupuestarias lo permitían, con nula gestión e inexistente planificación de la política de recursos humanos, alejando cualquier atisbo de enfoque estratégico, dejando aletargarse a las herramientas que el marco normativo ofrece para gestionar talento, adaptar recursos y mejorar la calidad del empleo y, en consecuencia del servicio público. Debe tenerse en cuenta que la gestión de personas se encuentra, en el ámbito local, fuertemente condicionada por una decisión del legislador, encomendar la jefatura de personal a la persona titular de la Alcaldía, decisión que no parece encajar demasiado en un modelo de gestión profesional, pues en muchos casos la dependencia política de un modo tan directo y en ámbitos de proximidad no conlleva sino a perpetuar las prácticas clientelares, sin que se pueda dar entrada a una planificación estratégica, dado el cortoplacismo de los tiempos que marcan los sucesivos procesos electorales, y la falta de cualificación técnica para afrontar, por parte de aquéllos que están sometidos al escrutinio del voto de muchos de sus empleados públicos (familiares y allegados), con valentía que requieren los cambios que deberían implementarse.

No cabe duda de que la nueva organización del trabajo que emana de la revolución digital, así como el incipiente pero contundente impacto de la robótica y los sistemas de colaboración público y privada debería alterar de inmediato el redimensionamiento del empleo público local. El régimen jurídico de los empleados públicos debe hacer posible la selección de los mejores candidatos, proporcionarles unas oportunidades de promoción profesional y una compensación por su trabajo que estimulen su dedicación al servicio público, así como la formación más apropiada para atenderlo y establecer un equilibrio adecuado entre sus derechos e intereses legítimos y sus deberes, obligaciones y responsabilidades, teniendo en cuenta que lo primordial es siempre garantizar el mejor servicio al conjunto de la ciudadanía, de especial impacto por los principios de proximidad y subsidiariedad que caracterizan al ámbito local.

A este marco básico necesitado de mejora, pretende ofrecer propuestas de solución el programa "Repensar la selección del empleo público", puesto en marcha por el Ministerio de Política Territorial y Función Pública, a través de la Secretaría General de Función Pública, sobre temas tan relevantes como la planificación de la selección; las amenazas y oportunidades del envejecimiento del empleo público; la capacidad y mérito: qué tipo de talento debe atraer y reclutar la Administración pública; el proceso selectivo y la igualdad y la transparencia en los procesos de selección y que tiene como objetivo identificar, contrastar y debatir las posiciones de las personas implicadas en la selección del empleo público de la Administración General del Estado.

Dentro de esta visión hacia el futuro de las entidades locales deben situarse las políticas de Gobierno Abierto y la implantación de los Objetivos del Desarrollo Sostenible (ODS) en el marco de la Agenda 2030. Respecto al primero, desde los pilares de transparencia, participación y colaboración, políticas cuyo máximo exponente puede apreciarse en el ámbito local, por la cercanía de la sociedad al mismo. En cuanto a los ODS, el papel de los gobiernos locales en el logro de los objetivos es crucial y depende en gran medida del capital humano para la ejecución de las políticas públicas, ya que todos los ODS incluyen metas relacionadas con competencias y responsabilidades de la esfera local y municipal, principalmente en la prestación de servicios básicos y en la promoción de un desarrollo territorial endógeno, inclusivo y sostenible. 


\subsection{Propuestas de ajuste en el empleo público local para un futuro que ya es presente}

Al margen de la existencia de procesos de revisión del marco normativo del estatuto básico del empleo público, la adecuación del empleo público local a las necesidades de futuro, y, en particular, al escenario marcado por las tendencias de digitalización, podría alcanzarse sobre la base de las siguientes propuestas:

- Reforzar los planes de captación del talento para el servicio público, emulando las experiencias de nuestro entorno y previendo la posibilidad de acudir a modelos de colaboración con las universidades, subvenciones de formación, que faciliten la visión del mundo local como un ámbito profesional de interés para el talento.

- Revisar el modelo de selección, aun cuando el marco legal básico no se modifique, el actual no lo impide, pues muy poco se ha avanzado en relación a los primeros sistemas de «oposiciones libres», implantados en el s. XIX (Jiménez, 2018).

- Gestionar el relevo generacional, por una parte, fortaleciendo las capacidades de los empleados públicos de mayor edad y estableciendo sistemas de transferencia del conocimiento y retención del know-how.

- Fortalecer el perfil de las competencias profesionales con la finalidad de que aporten valor añadido (creatividad, iniciativa, innovación, pensamiento crítico, soft skills, etc.), exigiendo tales competencias en procesos selectivos o en la provisión de puestos de trabajo.

- Profesionalizar la Dirección Pública local. Debe apostarse por la configuración de una una Dirección Pública profesionalizada, en particular en los niveles directivos, alejada de los núcleos de poder político y de las capturas que la proximidad de los niveles de gobierno y administración pueden permitir, y con un desempeño objetivo e imparcial de sus funciones.

- Impulsar un clima ético organizacional. Mediante la identificación de los valores de la entidad con los empleados públicos, por ello, más allá de la introducción de este tipo de conocimientos en los sistemas de acceso resulta capital diseñar un sistema de integridad institucional que garantice la satisfacción de los objetivos perseguidos por la entidad.

- Gestionar el conocimiento. No se da suficiente relevancia a la gestión del conocimiento en las entidades locales, gestión que se encuentra precisamente en el personal a su servicio, es decir, es un conocimiento individual, tácito, que debe convertirse en explícito para socializarse con el conjunto de la organización, compartirlo y ponerlo al servicio de todos.

- Planificar y ordenar la gestión de personas. En dicho sentido, llevar a cabo una gestión planificada de vacantes (Gorriti, 2018), que detecte las tareas que se van a automatizar a corto/medio plazo, amortizando aquellos puestos o dotaciones que sea vean más afectados por la automatización de tareas, redefinir asimismo las funciones y tareas de los que se mantenga, y crear, en paralelo, nuevos puestos de trabajo que hagan frente a las necesidades a medio plazo de las organizaciones locales (titulaciones STEM).

- Solucionar las deficiencias de personal de puestos especializados mediante alguna de las siguientes opciones: agrupación de puestos, sobre la articulación de un modelo similar al establecido para los FHN en el RD 128/2018, que contempla que las Entidades Locales cuyo volumen de servicios o recursos sea insuficiente o crear Cuerpos técnicos provinciales de asistencia municipal, en particular, vinculados a puestos TIC.

- Profesionalizar la selección de los empleados públicos locales, promoviendo la existencia de órganos de selección permanentes exógenos, vinculados a los institutos de administración pública o a las Diputaciones provinciales o CC.AA uniprovinciales.

- Reskilling permanente en el seno de la organización, pasando de modelos de aprendizaje tradicionales a aprendizajes en línea con el nuevo modelo de administración, a modo de palancas de cambio que permitan garantizar, en todo momento, la adecuación a las demandas de la sociedad, alineando ciudadanía y administración.

- Desarrollar la carrera profesional a través de la movilidad intermunicipal pero también horizontal entre el conjunto de administraciones públicas, frente a visiones exclusivamente vinculadas a la mejora retributiva, sin apenas modificación alguna en el puesto de trabajo, y cuya ausencia de mayor desarrollo quizás pueda atribuirse a la llegada de la crisis.

- Evaluación del desempeño. Para que la evaluación responda a la filosofía y finalidad prevista inicialmente en el EBEP debe estar basada y diseñarse desde un análisis del puesto de trabajo, 
comprendiendo comportamientos laborales relevantes bajo el dominio del empleado público, con un proceso sistemático basado en el principio de igualdad y en un estándar de desempeño preestablecido (Gorriti, 2011).

\section{CONCLUSIONES}

Los factores que impactan en este horizonte de urgencia en la redefinición del modelo de empleo público local no son pocos, pero a efectos de determinar su mayor incidencia podemos apuntar la globalización, el envejecimiento de la población, con el consiguiente reto demográfico, la revolución tecnológica con todas sus derivadas y los profundos cambios en los modelos productivos, en un entorno de crisis económica y post crisis. Por ello, uno de los retos a los que se enfrentan las entidades locales es la adecuación de los perfiles profesionales a los desafíos presentes y futuros, siendo preciso dar prioridad a la captación de inteligencia y talento e incorporar al sector público nuevas competencias en las áreas más conectadas con la innovación, y capacidades para la asunción del nuevo escenario. Es en este punto donde debemos subrayar la importancia de las competencias profesionales, tanto tecnológicas como de soft law para el desempeño de sus funciones, con una actitud crítica, capacidad de preguntar y de cuestionar en permanente clave de mejora y para ello debe conocer y comprender el entorno digital y ejercer un desempeño íntegro, basado en una actuación ética, conforme a unos principios y valores, sino de que dichas competencias deben asegurarse en el conjunto de la organización, garantizando la adecuación de los modelos de captación de talento público pero también el reskilling del ya existente.

No puede negarse la evidencia de que existe un considerable déficit en la gestión de personas en gran parte de las entidades locales, máxime desde el punto de vista de la planificación, pero tan importante es contar con el adecuado marco normativo para asumir este proceso de transformación como contar con las herramientas de gestión necesarias, ágiles y flexibles por definición, que permitan afrontar los nuevos retos y ofrecer soluciones innovadoras a problemas que se generan ante inéditos escenarios (Castillo, 2011). Como hemos visto, éste es el modelo hacia el que están evolucionando los países de nuestro entorno, donde debemos recordar la creación del Senior Civil Service en el Reino Unido, estructura profesional que se debe precisamente al impulso político o la propia Ecole Nationale d'Administration (ENA) en Francia, aunque en este último caso se encuentra sujeta a una revisión en profundidad, pues ya han incluido en su agenda de reformas una revisión tan profunda de su modelo que algunos hablan de que no se debe excluir su supresión, en busca de un modelo más moderno (Mapelli, 2018).

Los nuevos retos a los que se enfrentan las entidades locales en este s. XXI y la probabilidad de asumirlos con éxito está directamente relacionado con el capital humano y con la capacidad de gestión de los recursos humanos en este entorno VUCA. La relevancia de la inteligencia emocional y las soft skills ofrecerá múltiples ventajas, básicamente en un doble plano, para poder gestionar las resistencias que generará, las dificultades que su implantación tendrá, y resolver las situaciones que se derivarán de la misma (nuevos empleos, transformación de otros y desaparición de algunos, capacitación en nuevas competencias profesionales, etc.), así como para convertir a la administración local, la más próxima al ciudadano y que presta servicios básicos a la ciudadanía, en el modelo de gestión de futuro.

Resulta necesaria la conexión entre la administración local de futuro y el empleo público de futuro, pues será la demanda de servicio público la que determine en mayor medida el tipo de personal, su nivel de capacitación y las destrezas y competencias que deberán exigirse en su desempeño. La metodología STEEP (Aguilar, 1967) agrupa las tendencias en torno a 5 ámbitos: sociales, tecnológicos, económicos, medioambientales, y políticos. La transformación que corresponde asumir a las entidades locales debe realizarse desde esa visión adaptativa del sector público, que comprenda las nuevas (y en ocasiones complejas) realidades sociales, que fomente la transparencia, la innovación, el gobierno abierto, el trabajo en equipo y una posición proactiva del sector público, basada en la resiliencia. Considerar que esta revolución es únicamente la transformación digital, con una visión basada exclusivamente en la utilización y el conocimiento de las tecnologías y herramientas digitales más sofisticadas, en la digitalización de los procesos, sería un error, pues al contrario, las nuevas tecnologías son la excusa, la coartada que origina esta revolución, que corresponde liderar a las personas que prestan sus servicios en las entidades locales.

La urgencia de abordar este proceso de transformación del empleo público se pone de manifiesto en una frase cuya autoría corresponde a la Comisión para el Estudio y Preparación del EBEP (2015): «No puede existir una buena Administración allí donde el sistema de empleo público es deficiente». 


\section{REFERENCIAS BIBLIOGRÁFICAS}

AA.VV (2017): Nuevos tiempos para la función pública. Madrid: INAP.

ARRIBAS, D. (2014): "Algunos apuntes sobre los tests psicológicos y su uso para la selección de personal en la administración pública", en Revista Vasca de Gestión de Personas y Organizaciones Públicas, núm 7, págs. 24-35.

BAUMAN, Z. (2002): Modernidad Líquida. México: Fondo de Cultura Económica.

BOTO, A. (2016): "Modernización en empleo público: la Ley francesa 2016-483, de 20 de abril, sobre deontología, derechos y obligaciones de los funcionarios", en Revista General de Derecho Administrativo, núm. 43.

BUSSO, M.; BASSI, M.; URZÚA, S.; VARGAS, J. (2011): Desconectados: Habilidades, educación y empleo en América Latina. Banco Interamericano de Desarrollo. https://publications.iadb.org/es/desconectados-habilidadeseducacion-y-empleo-en-america-latina.

CAMPOS, C.; FERREIRA, J.; SANTISO, M.; VAQUERO, A. (2017): Radiografía de la gestión de recursos humanos en los Ayuntamientos de menos de 50.000 habitantes. Documento 8/2017. Red Localis. https://drive.google.com/ file/d/1WXoc0tbpJGKX3Y-Qs/c3iSt1SkFFeZIT/view.

CAMPOS, C. (2020): "Administración electrónica, empleo público y teletrabajo: el efecto catalizador del COVID-19", RODRÍGUEZ, J. F.; ATIENZA, E.: Retos jurídicos ante la crisis del COVID-19. Madrid: Wolters Kluwer.

CASTILLO, F. (2011): "El empleo público local: situación actual y perspectivas", en Revista Aragonesa de Administración Pública, núm. Monográfico XIII, (Ejemplar dedicado a: El empleo público en Aragón y tendencias de futuro), págs. 97-127.

CATALÁ, R.; CORTÉS, O. (2019): Administración 2030: Una visión transformadora. Observatorio del Sector Público, ESADE-PWC.

CUENCA, J. (2019): "Las problemáticas y desafíos del personal al servicio de las entidades locales: una visión general”, III Informe Red Localis, Retos de las entidades locales ante la transformación digital de la gestión pública. Madrid: Wolters Kluwer.

DE LA NUEZ, E. (2018): “Acceso a la función pública: atraer talento y cambiar el modelo”, en Revista Vasca de Gestión de Personas y Organizaciones Públicas, núm. Especial 2, págs. 86-97.

ESTEBAN, A. (2019): “La evolución del empleo público local en los últimos 40 años”, en Blog Instituto de Derecho Local. http://www.idluam.org/blog/la-evolucion-del-empleo-publico-local-en-los-ultimos-40-anos/.

FONDEVILA, J. (2008): La Selección y Pérdida de la Condición de Empleado Público, especial referencia a su aplicación en la Administración. Barcelona: Atelier.

FUENTETAJA, J. A. (2015): "Función pública local y reforma local”, en Cuadernos de Derecho Local, núm. 37, págs. 41-75.

FUKUYAMA, F. (2016): Orden y decadencia de la política. Barcelona: Deusto.

GARCÍA, O.; RAMIÓ, C.; SALVADOR, M. (2007): Los determinantes de la gestión de la externalización en Cataluña. Barcelona: Fundación Carles Pi y Suñer.

GORRITI, M. (2011): "La evaluación del desempeño: análisis, retos y propuestas: Una aplicación a la Comunidad Autónoma de Aragón", en Revista Aragonesa de Administración Pública, núm. Monográfico 13. (Ejemplar dedicado a: El empleo público en Aragón y tendencias de futuro).

GORRITI, M. (2018): "Innovar en selección desde la evidencia empírica y las nuevas competencias”, en Revista Vasca de Gestión de Personas y Organizaciones Públicas, núm. Especial 2.

GOBIERNO DE ESPAÑA (2020): España Digital 2025. https://www.lamoncloa.gob.es/presidente/actividades/ Documents/2020/230720-EspañaDigital 2025.pdf.

GOBIERNO DE ESPAÑA (2020). Estrategia Nacional de Inteligencia Artificial. https://portal.mineco.gob.es/ RecursosNoticia/mineco/prensa/noticias/2020/201202 np ENIAv.pdf.

GUTIÉRREZ, A.; MATUS, O. (2015): "Habilidades Blandas: Ūna ventaja competitiva en la formación tecnológica", en GINT Journal of Industrial Neo-Technologies. https://www.jint.usach.cl/sites/jint/files/art._9_print_v2n1jint006-15_ V3.0_0.pdf.

HIDALGŌ, M. A. (2018): El empleo del futuro. Barcelona: Deusto.

INSTITUTO ANDALUZ DE ADMINISTRACIÓN PÚBLICA (2017): Libro Blanco sobre Metodologías Innovadoras de Formación en la Administración Pública. Sevilla: Instituto Andaluz de Administración Pública. https://www. juntadeandalucia.es/export/drupaljda/publicacion/19/10/texto_completo_libro_blanco_vol_l.pdf.

JIMÉNEZ, R. (2020): "Los empleados (públicos) mirando al futuro", en blog La mirada institucional. https:// rafaeljimenezasensio.com/2020/02/16/los-empleados-publicos-mirando-al-futuro/.

JIMÉNEZ, R. (2019): "El futuro de los juristas en la administración pública”, en blog La mirada institucional. https:// rafaeljimenezasensio.com/2019/03/24/el-futuro-de-los-juristas-en-la-administracion-publica/.

JIMÉNEZ, R. (2018): "Repensar la selección de empleados públicos: momento actual y retos de futuro", en Revista Vasca de Gestión de Personas y Organizaciones Públicas, núm. Especial 2.

LONGO, F. (2019): "La administración pública en la era del cambio exponencial. Hacia una gobernanza exploratoria", en Revista Vasca de Gestión de Personas y Organizaciones Públicas, núm. Especial 3 (Serie Innovación pública).

LOSA, V.; VAQUERO, A. (2020): La problemática de la despoblación rural y el reto demográfico ¿Qué se puede hacer desde el ámbito local? Documento núm. 14/2020. Red Localis. 
MAPELLI, C. (2018): "La visión comparada: nuevos sistemas de selección de la alta función pública en las democracias avanzadas”, en Revista Vasca de Gestión de Personas y Organizaciones Públicas, núm. Especial 2.

OCDE (2017): Government at a Glance 2017. https://www.oecd.org/gov/government-at-a-glance-2017-highlights-en. pdf.

OCDE (2018): Recomendación del Consejo sobre el Liderazgo y Capacidad en la Función Pública. OCDE/ LEGAL/0445 (Serie: Instrumentos jurídicos de la OCDE). https://www.oecd.org/gov/pem/recomendacion-delconsejo-sobre-liderazgo-y-capacidad-en-la-funcon-publica.pdf.

OSBORNE, M. A.; FREY, C. B. (2017): "The future of employment: How susceptible are job to computerisation?", en Technological Forecasting and Social Change, vol. 114. págs. 254-280. https://doi.org/10.1016/j. techfore.2016.08.019.

PACHECO, N. E.; BERROCAL, P. F. (2004): "La inteligencia emocional: Métodos de evaluación en el aula", en Revista Iberoamericana de Educación, vol. 34, núm. 1. https://doi.org/10.35362/rie3412887.

PEREDA, F. J.; LÓPEZ-GUZMÁN, T.; GONZÁLEZ SANTA CRUZ, F. (2018): "La inteligencia emocional como habilidad directiva. Estudio aplicado en los municipios de la provincia de Córdoba (España)", en Nóesis. Revista de Ciencias Sociales y Humanidades, vol. 27, núm. 53. https://doi.org/10.20983/noesis.2018.1.5.

POVEDANO, D. (2019): “Un modelo de gestión del empleo público innovador ¿es posible?”, en III Informe Red Localis, Retos de las entidades locales ante la transformación digital de la gestión pública. Madrid: Wolters Kluwer.

PRIMOFF, E. S. (1975): How to prepare and conduct job element examinations. Washington: D.D.:U.S. Government Printing Office.

RAMIÓ, C. (2017a): La Administración Pública del Futuro, Horizonte 2050: Instituciones, Política, Mercado y Sociedad de la Innovación. Madrid: Tecnos.

RAMIÓ, C. (2017b): "El volumen del empleo público en el futuro: un análisis de prospectiva”, en El Blog esPublico. https://www.administracionpublica.com/el-volumen-del-empleo-publico-en-el-futuro-un-analisis-de-prospectiva/.

RAMIÓ, C. (2018): Inteligencia Artificial y Administración Pública. Madrid: Catarata.

ROSILLO, L. (2019): "Contra el \#edadismo: Planificación de la longevidad... madurez creativa”, en Blog Laura Rosillo. http://Irosilloc.blogspot.com/2019/03/contra-el-edadismo-planificacion-de-la.html.

ROYO-VILLANUEVA, S. (1950): "La formación de los empleados públicos", en Revista de Administración Pública, núm. 2, págs. 11-34.

RUIZ, M. ( 2017): Ser digital. Madrid: Kolima Books.

SÁNCHEZ MORÓN, M. (2014): "El empleo público local tras la Ley de Racionalización y Sostenibilidad de la Administración Local. El estado de la cuestión”, en Seminari sobre relacions collectives, Federació de Municipis de Catalunya, FMC. http://cemical.diba.cat/es/publicaciones/ficheros/Sanchez_Moron_Miguel_SRC_2014.pdf.

SANCHEZ MORÓN, M. (2012): "Consideraciones sobre la reforma del régimen de acceso al empleo público", en Revista Catalana de Dret Públic, núm. 45, págs. 47-62.

SEISDEDOS, C. (2019): "El aprendizaje como palanca de cambio y modernización del sector público", en III Informe Red Localis, Retos de las entidades locales ante la transformación digital de la gestión pública. Madrid: Wolters Kluwer.

WRIGHT, P., GARDNER, P.; MOYNIHAN, L. (2003): "The impact of HR practices on the performance of the business", en Human Resource Management Journal, vol. 13, núm. 3. https://doi.org/10.1111/j.1748-8583.2003.tb00096.x. 